\title{
Number of outer electrons as descriptor for adsorption processes on transition metals and their oxides
}

Calle-Vallejo, Federico; Inoglu, Nilay G.; Su, Hai-Yan; Martinez, Jose I.; Man, Isabela C.; Koper, Marc T. M.; Kitchin, John R.; Rossmeisl, Jan

\section{Published in:}

Chemical Science

Link to article, DOI:

$10.1039 / \mathrm{c} 2 \mathrm{sc} 21601 \mathrm{a}$

Publication date:

2013

Document Version

Publisher's PDF, also known as Version of record

Link back to DTU Orbit

Citation (APA):

Calle-Vallejo, F., Inoglu, N. G., Su, H-Y., Martinez, J. I., Man, I. C., Koper, M. T. M., Kitchin, J. R., \& Rossmeisl, J. (2013). Number of outer electrons as descriptor for adsorption processes on transition metals and their oxides. Chemical Science, 4(3), 1245-1249. https://doi.org/10.1039/c2sc21601a

\section{General rights}

Copyright and moral rights for the publications made accessible in the public portal are retained by the authors and/or other copyright owners and it is a condition of accessing publications that users recognise and abide by the legal requirements associated with these rights.

- Users may download and print one copy of any publication from the public portal for the purpose of private study or research.

- You may not further distribute the material or use it for any profit-making activity or commercial gain

- You may freely distribute the URL identifying the publication in the public portal 


\section{Chemical Science}

Cite this: Chem. Sci., 2013, 4, 1245

\section{Number of outer electrons as descriptor for adsorption processes on transition metals and their oxidest}

Received 26th September 2012

Accepted 2nd January 2013

DOI: $10.1039 /$ c2sc21601a

www.rsc.org/chemicalscience

\author{
Federico Calle-Vallejo, ${ }^{a}$ Nilay G. Inoglu, ${ }^{\mathrm{b}}$ Hai-Yan Su, ${ }^{\mathrm{c}}$ José I. Martínez, ${ }^{\mathrm{d}}$ \\ Isabela C. Man, ${ }^{c}$ Marc T. M. Koper, ${ }^{\star a}$ John R. Kitchin ${ }^{b}$ and Jan Rossmeisl ${ }^{c}$
}

The high catalytic activity of transition metal oxides is well known. ${ }^{1-4}$ They are often inexpensive, versatile and stable materials traditionally used at high temperatures and nowadays also attractive for low-temperature applications. ${ }^{5-7}$ Substantial effort has been made to rationalize the trends in their bulk and surface properties so as to pinpoint active and stable catalysts to help reduce or completely replace noble metals in applications such as fuel cells.,4,6-11 Although successful designs of oxide catalysts resulting from comprehensive understanding of their surface chemistry are rare, recent works have shed light on this matter aided by atomic-scale simulations. ${ }^{8-19}$

Since the adsorption energies $\left(\Delta E_{\mathrm{ADS}}\right)$ of reaction intermediates determine to a large extent the catalytic activity, it is important to find the electronic-structure factors that influence them. However, there are neither general models for the rationalization and prediction of trends in reactivity among transition metal oxides nor links between the adsorption behavior of transition metals and their oxides. The case of pure transition metals and their alloys is different, as the "d-band model" has proved useful in explaining trends in $\Delta E_{\mathrm{ADS}}$ and making successful predictions about the catalytic activity. ${ }^{20-23}$ Within this model the reactivity of transition metals can be readily related to characteristics of the surface d-band, with the d-band center being the most used descriptor. ${ }^{22,24-26}$ However, it is unknown whether this framework can be extended to

\footnotetext{
${ }^{a}$ Leiden Institute of Chemistry, Leiden University, Einsteinweg 55, 2333 CC, Leiden, The Netherlands. E-mail: m.koper@lic.leidenuniv.nl; Fax: +31 715274451

${ }^{b}$ Department of Chemical Engineering, Carnegie Mellon University, Pittsburgh, Pennsylvania, 15213, USA

${ }^{c}$ Center for Atomic-scale Material Design, Department of Physics, Technical University of Denmark, 2800 Kongens Lyngby, Denmark

${ }^{d}$ Departamento de Física Teórica de la Materia Condensada, Universidad Autónoma de Madrid, ES-28049, Madrid, Spain

$\dagger$ Electronic supplementary information (ESI) available: Additional calculation details and crystallographic data, methodology used to make the grids, ${ }^{*} \mathrm{O}$ and

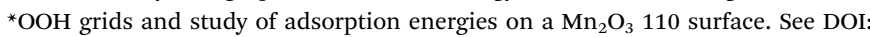
$10.1039 / \mathrm{c} 2 \mathrm{sc} 21601 \mathrm{a}$
}

transition metal oxides, materials in which $\Delta E_{\mathrm{ADS}}$ results from an interplay of several factors including the number and the spatial configuration of the metal atoms and their ligands, the oxidation state of the transition metals and the interactions between the active site and the adsorbates.

A remarkable example of the rational design of oxide catalysts is the work of Suntivich et al., who correlated the experimental trends in activity for the oxygen reduction and evolution reactions (ORR and OER, respectively) on perovskite oxides $\left(\mathrm{AMO}_{3}\right)$ with the filling of the $\mathrm{e}_{\mathrm{g}}$ orbitals of the transition metal $\mathrm{M}$ at the surface. ${ }^{6,7,27}$ Noting that the d orbitals of atoms in the $\mathrm{M}$ sites split in a low-energy triplet $\left(t_{2 g}\right)$ and a high-energy doublet $\left(\mathrm{e}_{\mathrm{g}}\right)$ due to their octahedral symmetry, they found that an occupation of $\sim 1$ in $e_{g}$ renders maximum catalytic activity for both reactions. On the other hand, various surface parameters such as the energetics of formation of oxygen vacancies and the oxygen p-band center in the lattice have also been shown to describe the activity trends of $\mathrm{AMO}_{3}$ for solid oxide fuel cells. ${ }^{28}$ Moreover, several works have shown the importance of periodicity in the reactivity of transition metal compounds. ${ }^{2,27,29}$

In an attempt to gain a comprehensive understanding of the relationship between the electronic structure and adsorption properties of pure and oxidized transition metal surfaces, herein we consider the adsorption of the ORR-OER intermediates, namely ${ }^{*} \mathrm{O},{ }^{*} \mathrm{OH}$, and ${ }^{*} \mathrm{OOH},{ }^{9,30,31}$ and describe the trends in terms of "outer" electrons, defined as the number of valence electrons remaining on the metal atom upon oxidation, e.g. 6 for pure $\mathrm{Cr}, 4$ for $\mathrm{Cr}^{2+}$ in $\mathrm{CrO}, 3$ for $\mathrm{Cr}^{3+}$ in $\mathrm{LaCrO}_{3}$, and 2 for $\mathrm{Cr}^{4+}$ in $\mathrm{SrCrO}_{3}$, see the ESI, $\uparrow$ for further details. We present the following case studies: (1) within a given kind of compound we vary the transition metal in the active site in order to analyze the effect of changing the number of outer electrons on $\Delta E_{\mathrm{ADS}}$. (2) For a given $3 \mathrm{~d}$ metal we vary its oxidation state in order to analyze the effect of changing the valence shell filling on $\Delta E_{\mathrm{ADS}}$. A third case study is shown in the ESI, $\uparrow$ where the stoichiometry and the oxidation numbers are fixed (in the $\mathrm{Mn}_{2} \mathrm{O}_{3} 110$ surface), but the coordination numbers of the surface metal atoms are 
different. In that case, coordination numbers can be used to capture the trends in $\Delta E_{\mathrm{ADS}}$. Coupling the findings of (1) and (2), we show that $\Delta E_{\mathrm{ADS}}$ and outer electrons are linked through a well-defined grid that explains the existence of scaling relationships between the energetics of adsorbed species and can be predictive.

\section{Methods}

The crystallographic details of the oxide surfaces are provided in the ESI, $\uparrow$ together with images of the simulated surfaces. The DFT calculations were made with the plane-wave code Dacapo, using ultrasoft pseudopotentials and the RPBE xc-functional, ${ }^{32}$ with converged plane wave cutoffs of $400 \mathrm{eV}$ for $\mathrm{AMO}_{3}$, and $450 \mathrm{eV}$ for MO and M. In all cases a density cutoff of $500 \mathrm{eV}$ was used. We used 4 layers of atoms for the simulations, fixing the two in the bottom to the optimized bulk distances and allowing the two topmost and the adsorbates to fully relax. The binding energies were converged with respect to the number of layers in the calculations and variations of less than $0.05 \mathrm{eV}$ were found between 4 layers and 6 layers for selected $\mathrm{AMO}_{3}$. Atomic relaxations were done with the quasi-Newton minimization scheme, until a maximum force below $0.05 \mathrm{eV} \AA^{-1}$ was achieved on all of the relaxed atoms. The Brillouin zone of all systems was sampled with $4 \times 4 \times 1$ Monkhorst-Pack grids, achieving convergence of at least $0.05 \mathrm{eV}$ per adsorbate with respect to $k$ points in all cases. The self-consistent RPBE density was determined by iterative diagonalization of the Kohn-Sham Hamiltonian at $k_{\mathrm{B}} T=0.1 \mathrm{eV}$, using Pulay mixing of densities, and all total energies were extrapolated to $k_{\mathrm{B}} T=0 \mathrm{eV}$. Spin polarized calculations were carried out for all oxides and for $\mathrm{Cr}$, $\mathrm{Mn}, \mathrm{Fe}, \mathrm{Co}$ and Ni in their metallic phases.

\section{Results and discussion}

Fig. 1 shows the change in adsorption energies of ${ }^{*} \mathrm{O},{ }^{*} \mathrm{OH}$, and ${ }^{*} \mathrm{OOH}$ (denoted by $\Delta E_{\mathrm{O}}, \Delta E_{\mathrm{OH}}$ and $\Delta E_{\mathrm{OOH}}$, respectively) among $3 \mathrm{~d}$ metals from $\mathrm{Sc}$ to $\mathrm{Cu}$, which have null formal oxidation state; monoxides (MO), with oxidation state +2 ; and $\mathrm{AMO}_{3}$, for which we examined two different oxidation states for $\mathrm{A}$ and $\mathrm{M}$ : when the A site is occupied by La or Y, both A and M have oxidation states of +3 . Alternatively, when the A site is occupied by $\mathrm{Ca}, \mathrm{Sr}$, or $\mathrm{Ba}$, then $\mathrm{A}$ and $\mathrm{M}$ have oxidation states of +2 and +4 , respectively.

Note that in all cases in Fig. 1 the slope of $\Delta E_{\mathrm{O}}$ is about twice those of $\Delta E_{\mathrm{OH}}$ and $\Delta E_{\mathrm{OOH}}$, and that the trends for the latter two are approximately parallel. These features are responsible for the existence of scaling relationships between $\Delta E_{\mathrm{O}}$ and $\Delta E_{\mathrm{OH}}$ and $\Delta E_{\mathrm{O}}$ and $\Delta E_{\mathrm{OOH}}$, both with a slope of $\sim 0.5$, and the scaling between $\Delta E_{\mathrm{OH}}$ and $\Delta E_{\mathrm{OOH}}$ with a slope of $\sim 1 .^{30,31,33,34}$ We will come back to this point later. Based on Fig. 1, we conclude that $\Delta E_{\mathrm{ADS}}$ weakens systematically with increasing number of outer electrons. For metals the picture is clear, as the d-band model predicts high reactivity (strong binding) for early transition metals and low reactivity (weak binding) for late transition metals. ${ }^{20}$ Considering that upon oxidation $3 \mathrm{~d}$ transition metals first lose their $4 \mathrm{~s}$ electrons and thus the outer electrons are

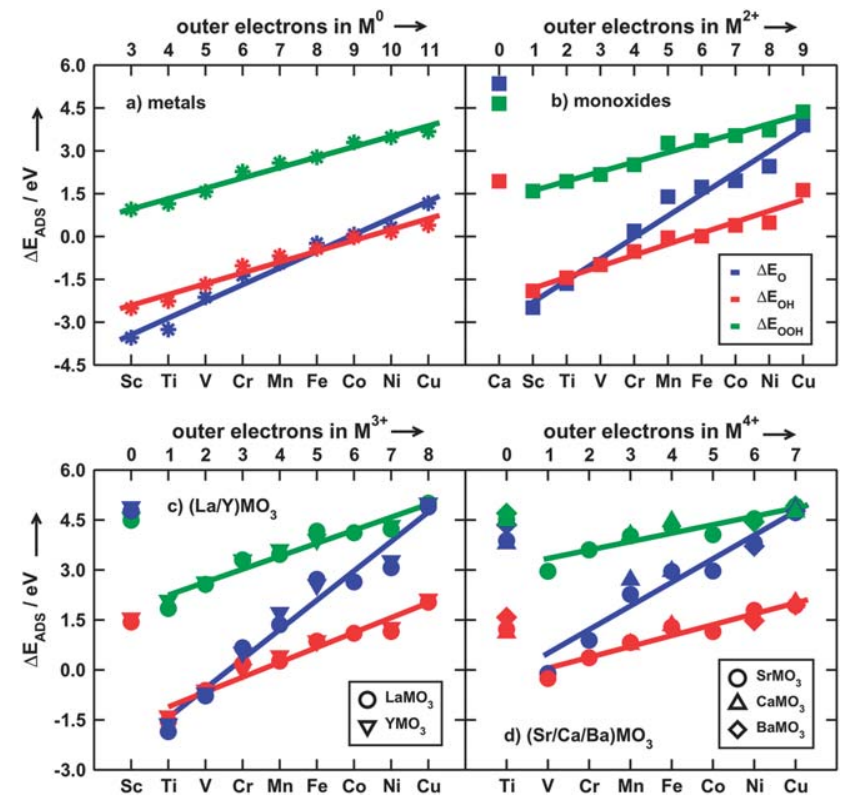

Fig. 1 Trends in $\Delta E_{\mathrm{O}}$ (blue), $\Delta E_{\mathrm{OH}}$ (red) and $\Delta E_{\mathrm{OOH}}$ (green) on: (a) metals (stars), (b) monoxides (squares), (c) La- (circles) and Y-perovskites (triangles down), and (d) Sr- (circles), Ca- (triangles up), and Ba-perovskites (diamonds). In all cases, an increase in the number of outer electrons weakens $\Delta E_{\mathrm{ADS}}$, except for closed-shell compounds. Note that only slight differences in adsorption energies are observed for perovskites with a given metal at the $M$ site and metals with the same oxidation number at the $A$ site.

found in the d-band, we explain the trends as follows: although their oxidation states are different, $\mathrm{MO},(\mathrm{La} / \mathrm{Y}) \mathrm{MO}_{3}$ and $(\mathrm{Sr} / \mathrm{Ca} / \mathrm{Ba}) \mathrm{MO}_{3}$ share the same coordination and spatial distribution of ligands, i.e. octahedral coordination. Thus, the splitting of their d-orbitals is identical and the ways in which those orbitals are filled are analogous (see the ESI $\dagger$ for further details). Since the $e_{g}$ and $t_{2 g}$ orbitals are normally nonbonding or antibonding (the $2 p$ orbitals of oxygen are the bonding orbitals in octahedral complexes), an increase in the number of outer electrons should correspond to a weakening of the binding strength. Nevertheless, there exist clear and justifiable exceptions to this statement in Fig. 1: closed-shell compounds, namely $\mathrm{LaScO}_{3}, \mathrm{YScO}_{3}, \mathrm{SrTiO}_{3}, \mathrm{CaTiO}_{3}, \mathrm{BaTiO}_{3}$, and CaO. These are inert because the oxidation states of their components are such that they fulfill the octet rule $\left(\mathrm{O}^{2-}\right.$ has the electronic configuration of $\mathrm{Ne})$ or the 18 -electron rule $\left(\mathrm{Sc}^{3+}, \mathrm{Ti}^{4+}\right.$ and $\mathrm{Ca}^{2+}$ resemble $\mathrm{Ar}, \mathrm{Y}^{3+}$ and $\mathrm{Sr}^{2+}$ resemble $\mathrm{Kr}$, and $\mathrm{La}^{3+}$ and $\mathrm{Ba}^{2+}$ resemble $\mathrm{Xe}$ ).

On the other hand, Fig. 2 shows the variations of $\Delta E_{\mathrm{O}}, \Delta E_{\mathrm{OH}}$ and $\Delta E_{\mathrm{OOH}}$ in Ni-based systems. As will be shown later, similar trends are observed among the other considered $3 \mathrm{~d}$ metals. The nearly linear scaling indicates that the oxidation state (or alternatively the number of outer electrons) can be used as a descriptor to understand the differences in $\Delta E_{\mathrm{ADS}}$ on different surfaces. Note that an increase in the oxidation state of $\mathrm{Ni}$ atoms corresponds to a weakening of $\Delta E_{\mathrm{ADS}}$. Since an increase in oxidation state is equivalent to a decrease in the number of outer electrons, the trends in Fig. 2 might seem counterintuitive when compared to those in Fig. 1. The explanation for this is as 


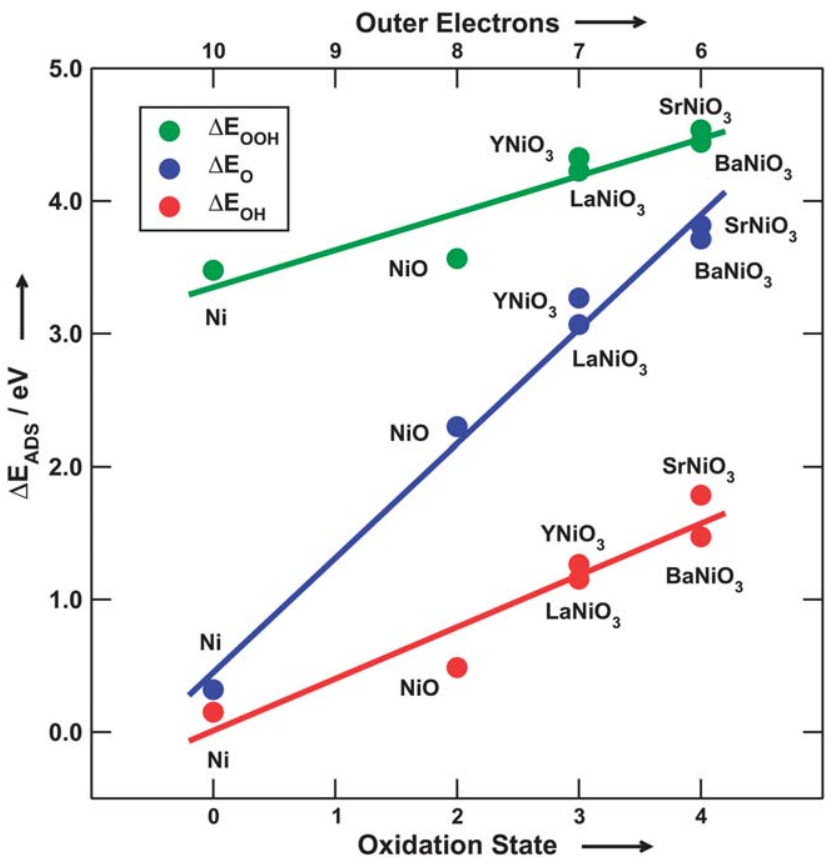

Fig. 2 Variations of $\Delta E_{\mathrm{O}}$ (blue), $\Delta E_{\mathrm{OH}}$ (red) and $\Delta E_{\mathrm{OOH}}$ (green) with the formal oxidation state of $\mathrm{Ni}$ atoms in various compounds. Note that an increase in oxidation state weakens $\Delta E_{\mathrm{ADS}}$ and that for a given oxidation state, the adsorption properties of different perovskites are similar.

follows: $\mathrm{Ni}$ atoms in the first layer of the (100) surfaces of $\mathrm{NiO}$, $(\mathrm{Y} / \mathrm{La}) \mathrm{NiO}_{3}$ and $(\mathrm{Sr} / \mathrm{Ba}) \mathrm{NiO}_{3}$ are coordinated to 5 oxygen atoms (four in the $X-Y$ plane and one in the subsurface layer, see ESI $\dagger$ ). Adsorbates complete the octahedron that is normally formed in the bulk by six oxygen ligands surrounding the $\mathrm{Ni}$ atom. Therefore, when a $\mathrm{Ni}$ ion at the surface is to receive a new electrophilic ligand, it must donate electrons to it in order to form the bond, and the more oxidized the metal atom is, the fewer electrons are available for bonding. This means that the strength with which highly oxidized cations create bonds that require their further oxidation is weak compared to atoms of the same species in lower oxidation states.

Fig. 1 and 2 suggest that the existence of nearly linear trends between $\Delta E_{\mathrm{ADs}}$ and outer electrons make it possible to condense all the information in a single plot. This is shown in Fig. 3 for $\Delta E_{\mathrm{OH}}$ (plots for $\Delta E_{\mathrm{O}}$ and $\Delta E_{\mathrm{OOH}}$ are provided in the ESI $\dagger$ ), where the number of outer electrons allows for the creation of an adsorption-energy grid in which the lines with positive slopes represent successive changes along the $3 \mathrm{~d}$ series, and those with negative slopes represent changes in oxidation states of a given transition metal. One important feature of Fig. 3 is that the magnitudes of the slopes in both directions are identical. The mean absolute error between the lines and the actual DFT values is $0.20 \mathrm{eV}$, which stands as an evidence of the predictive power of the grid. Another feature worth noting in Fig. 3 is that La- and Y-perovskites with the same metal at the $\mathbf{M}$ site, e.g. $\mathrm{YNiO}_{3}$ and $\mathrm{LaNiO}_{3}$, have similar adsorption properties, and the same can be said of $(\mathrm{Ca} / \mathrm{Sr} / \mathrm{Ba}) \mathrm{MO}_{3}$, e.g. $\mathrm{CaCrO}_{3}, \mathrm{SrCrO}_{3}$, and $\mathrm{BaCrO}_{3}$. This suggests that the primary electronic-structure parameter affecting $\Delta E_{\mathrm{ADS}}$ is the number of outer electrons and thus strain effects due to different lattice constants and/or elements in the A position are secondary. This phenomenon has also been observed in the bulk formation energies of these oxides (see ref. 8 and references therein). Similar grids could be constructed for $4 \mathrm{~d}$ and $5 \mathrm{~d}$ metals and their oxides, and the inclusion of rutile oxides would provide further insight. It seems possible to do so, as the trends in some bulk and surface properties of rutiles are well described by the number of $\mathrm{d}$ electrons or moments of the $d$ band. ${ }^{11,12}$ Predictions of $\Delta E_{\mathrm{ADS}}$ of oxide mixes and doped oxides is one of the possible uses of the grid, as $\mathrm{A}$ - and $\mathrm{M}$-site doping in $\mathrm{AMO}_{3}$ has proved an excellent option to tune the catalytic activities, ${ }^{6,7,16,27}$ and that recent studies have shown that doping may also improve those of rutiles. ${ }^{19}$ Note that a direct consequence of the existence of adsorption-energy grids is that two of them can be overlapped resulting in a single straight line, i.e. a scaling relation with a slope given by the ratio of the average slopes of the separate grids (see the ESI $\dagger$ for the grids of ${ }^{*} \mathrm{O}$ and ${ }^{*} \mathrm{OOH}$ ). This is shown in Fig. 4, where the different colors help illustrate the implicit trends among the cloud of points. It is important to say that while useful for applied studies such as Sabatier volcanoes, ${ }^{9,10,15,19,23}$ scaling relationships hide the trends among the points. Thus, from a fundamental point of view, the grids provide more insight as the trends are evident and the variations in $\Delta E_{\mathrm{ADS}}$ are linked to the electronic structure of the active site. Note that the intercept of the line in the left panel of Fig. 4 is $\sim 3.2 \mathrm{eV}$, an important number for the ORR-OER electrocatalysis, as it implies the existence of an intrinsic overpotential due to the scalability between the binding energies of the intermediates of these reactions. ${ }^{9,35,36}$

We remark that having common underlying electronicstructure descriptors leads to correlations in adsorption properties, ${ }^{33}$ mostly when the symmetries of the active sites are similar, in line with the concept of configurational correlation. ${ }^{37}$ The appearance of large surface reconstructions upon adsorption may cause severe deviations from linearity of scaling relationships. Furthermore, as a first approximation, we have not taken into account the effect of oxygen vacancies here. Although this interesting phenomenon is outside the scope of this study, it is worth noting its natural appearance in oxides in which the components are forced into a high oxidation state, e.g. Fe in $\mathrm{SrFeO}_{3}$, or its occurrence with doping, when host and guest atoms have different oxidation states. For some compounds these vacancies have proved relevant for the overall catalytic performance. ${ }^{17}$ Furthermore, we expect that the effect of oxygen vacancies can be rationally included into the model proposed here as the formation energies of these vacancies have been found to correlate well with the number of electrons of the transition metals at the $\mathbf{M}$ site in perovskite oxides and other electronic-structure descriptors. ${ }^{16,28}$ Finally, we would like to remark that the inclusion of the Hubbard-U correction (DFT + U method) in these calculations could be beneficial for a better estimation of the adsorption energies. Recent studies have shown that oxides with similar coordination numbers and spatial orientation exhibit comparable changes in adsorption energies between RPBE and $\mathrm{RPBE}+\mathrm{U}$, and the scaling relationships still hold, ${ }^{38}$ suggesting that the trends presented here would remain intact, although the actual numbers may change. 


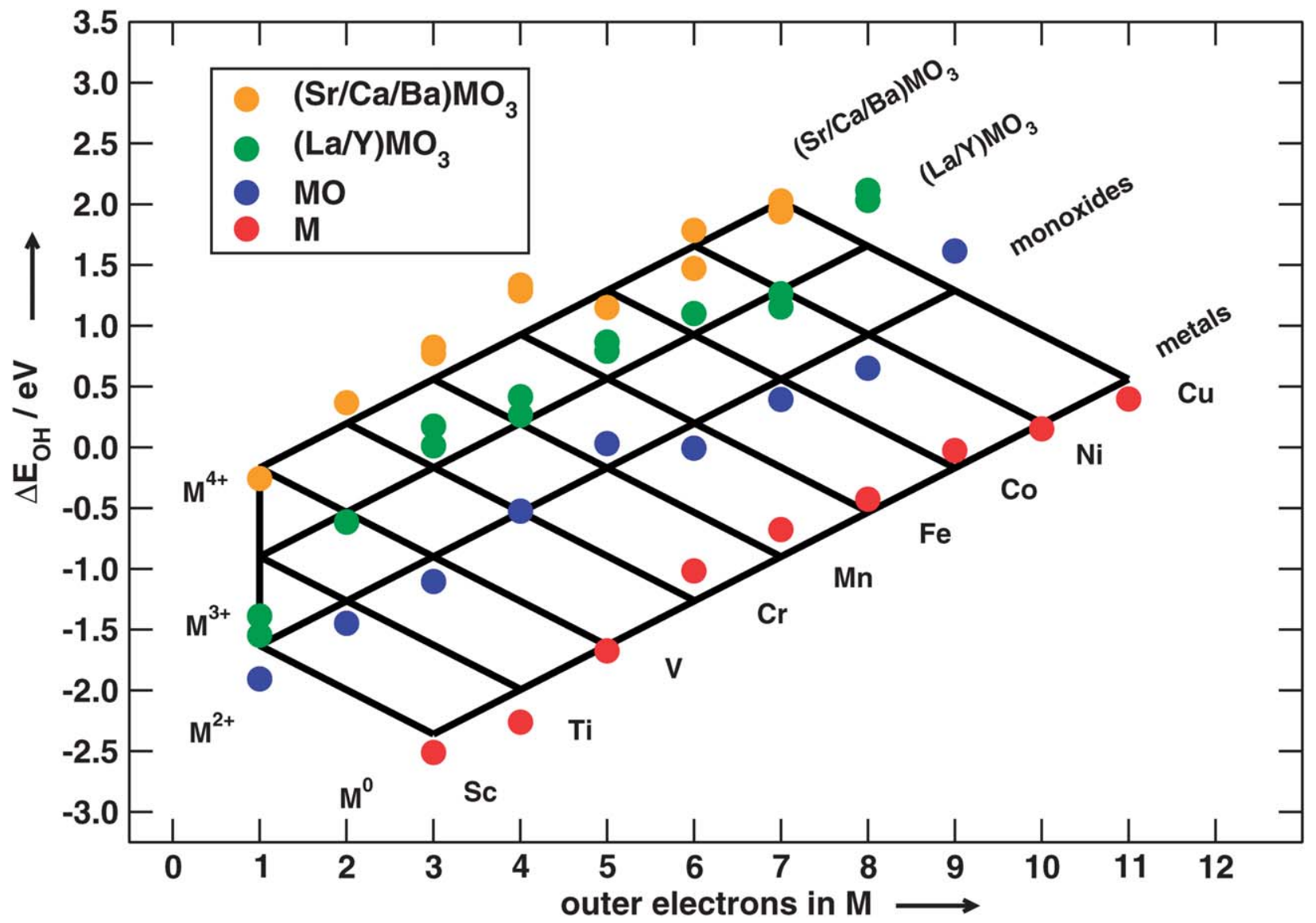

Fig. 3 Adsorption-energy grid of ${ }^{*} \mathrm{OH}$ on metals (red), monoxides (blue), La/Y perovskites (green), and $\mathrm{Sr} / \mathrm{Ca} / \mathrm{Ba}$ perovskites (orange), as a function of the number of outer electrons. The positive slopes (changing valence electrons) and the negative ones (changing oxidation states) have the same magnitude. Closed-shell compounds are not taken into account in the grid. Note that in all cases the black lines cross each other at integer numbers of outer electrons.
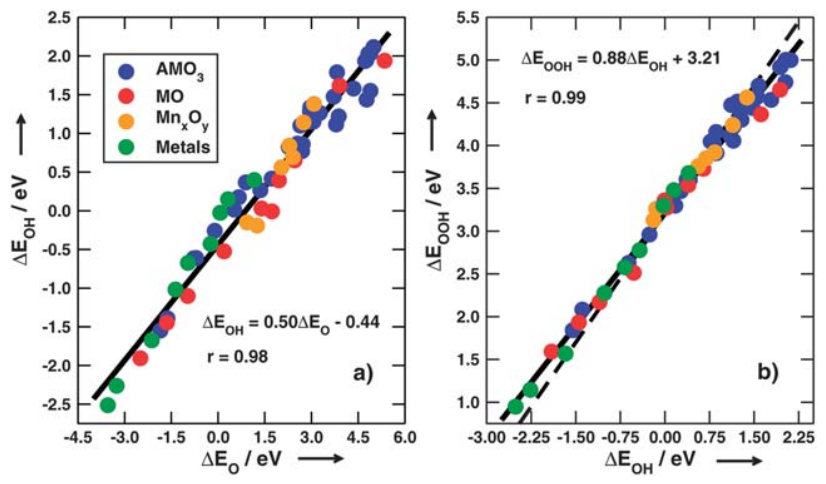

Fig. 4 Scaling relations between (a) $\Delta E_{\mathrm{OH}}$ and $\Delta E_{\mathrm{O}}$, (b) $\Delta E_{\mathrm{OOH}}$ and $\Delta E_{\mathrm{OH}}$ on metals (green), monoxides (red), perovskites (blue) and $\mathrm{Mn}_{2} \mathrm{O}_{3}$ (orange). In both panels the slopes are in agreement with the expected values (0.5 and 1$)$, and the intercept in (b) supports the findings in ref. 9, 35, 36 and 38. The dashed line in (b) corresponds to the regression reported therein.

This is also supported by the fact that other properties of perovskite oxides exhibit roughly linear trends when calculated with the GGA + U method, ${ }^{16,28}$ and that the formation energies calculated with standard DFT have a constant shift with respect to the experimental values. ${ }^{8}$

\section{Conclusions}

In an attempt to build a unified understanding of transition metals and their oxides not yet available in the literature, we have shown here that the number of outer electrons is a remarkable descriptor of the trends in adsorption energies of a large set of compounds. The use of this descriptor allows for the construction of adsorption-energy grids and explains the existence of scaling relationships among transition metals and their oxides. The grids are not only explanatory, but also potentially predictive, i.e. they could be used to predict the catalytic activity of doped oxides and oxide mixes towards several reactions of industrial and academic interest. In a broad context, our observations suggest that the main driving force for the reactivity of transition metals and their oxides is their search for maximum stability, i.e. the fulfillment of simple electron-counting rules by each and every component of the system. In view of this, golden rules in catalysis such as the Sabatier principle may start being understood in terms of the electronic structure of materials, which will ultimately lead to fully predictive models based on the simplest descriptors in chemistry: the number of electrons and the oxidation states. 


\section{Notes and references}

1 L. G. Tejuca, J. L. G. Fierro and J. M. D. Tascon, Adv. Catal., 1989, 36, 237-328.

2 J. O. Bockris and T. Otagawa, J. Electrochem. Soc., 1984, 131, 290-302.

3 Y. Matsumoto and E. Sato, Mater. Chem. Phys., 1986, 14, 397426.

4 S. Trasatti, Electrochim. Acta, 1984, 29, 1503-1512.

5 A. B. Stambouli and E. Traversa, Renewable Sustainable Energy Rev., 2002, 6, 433-455.

6 J. Suntivich, H. A. Gasteiger, N. Yabuuchi, H. Nakanishi, J. B. Goodenough and Y. Shao-Horn, Nat. Chem., 2011, 3, 546-550.

7 J. Suntivich, K. J. May, H. A. Gasteiger, J. B. Goodenough and Y. Shao-Horn, Science, 2011, 334, 1383-1385.

8 F. Calle-Vallejo, J. I. Martinez, J. M. Garcia-Lastra, M. Mogensen and J. Rossmeisl, Angew. Chem., Int. Ed., 2010, 49, 7699-7701.

9 I. C. Man, H.-Y. Su, F. Calle-Vallejo, H. A. Hansen, J. I. Martinez, N. G. Inoglu, J. Kitchin, T. F. Jaramillo, J. K. Norskov and J. Rossmeisl, ChemCatChem, 2011, 3, 1159-1165.

10 F. Studt, F. Abild-Pedersen, H. A. Hansen, I. C. Man, J. Rossmeisl and T. Bligaard, ChemCatChem, 2010, 2, 98-102.

11 D. J. Mowbray, J. I. Martinez, F. Calle-Vallejo, J. Rossmeisl, K. S. Thygesen, K. W. Jacobsen and J. K. Norskov, J. Phys. Chem. C, 2011, 115, 2244-2252.

12 J. I. Martinez, H. A. Hansen, J. Rossmeisl and J. K. Norskov, Phys. Rev. B: Condens. Matter Mater. Phys., 2009, 79, 045120.

13 A. Vojvodic, F. Calle-Vallejo, W. Guo, S. Wang, A. Toftelund, F. Studt, J. I. Martinez, J. Shen, I. C. Man, J. Rossmeisl, T. Bligaard, J. K. Noorskov and F. Abild-Pedersen, J. Chem. Phys., 2011, 134, 244509.

14 S. Chretien and H. Metiu, Catal. Lett., 2006, 107, 143-147.

15 H. A. Hansen, I. C. Man, F. Studt, F. Abild-Pedersen, T. Bligaard and J. Rossmeisl, Phys. Chem. Chem. Phys., 2010, 12, 283-290.

16 Y.-L. Lee, J. Kleis, J. Rossmeisl and D. Morgan, Phys. Rev. B: Condens. Matter Mater. Phys., 2009, 80, 224101.

17 V. Shapovalov and H. Metiu, J. Catal., 2007, 245, 205-214.

18 A. Vojvodic and J. K. Norskov, Science, 2011, 334, 1355-1356.

19 M. Garcia-Mota, A. Vojvodic, H. Metiu, I. C. Man, H.-Y. Su, J. Rossmeisl and J. K. Norskov, ChemCatChem, 2011, 3, 1607-1611.
20 B. Hammer and J. K. Norskov, in Advances in Catalysis, Vol 45: Impact of Surface Science on Catalysis, ed. B. C. Gates and H. Knözinger, Academic Press, San Diego, 2000, vol. 45, pp. 71-129.

21 J. R. Kitchin, J. K. Norskov, M. A. Barteau and J. G. Chen, Phys. Rev. Lett., 2004, 93, 156801.

22 M. Mavrikakis, B. Hammer and J. K. Norskov, Phys. Rev. Lett., 1998, 81, 2819-2822.

23 J. Greeley, I. E. L. Stephens, A. S. Bondarenko, T. P. Johansson, H. A. Hansen, T. F. Jaramillo, J. Rossmeisl, I. Chorkendorff and J. K. Norskov, Nat. Chem., 2009, 1, 552-556.

24 N. Inoglu and J. R. Kitchin, ACS Catal., 2011, 1, 399-407.

25 T. Bligaard and J. K. Norskov, Electrochim. Acta, 2007, 52, 5512-5516.

26 J. G. Chen, C. A. Menning and M. B. Zellner, Surf. Sci. Rep., 2008, 63, 201-254.

27 J. Suntivich, H. A. Gasteiger, N. Yabuuchi and Y. Shao-Horn, J. Electrochem. Soc., 2010, 157, B1263-B1268.

28 Y.-L. Lee, J. Kleis, J. Rossmeisl, Y. Shao-Horn and D. Morgan, Energy Environ. Sci., 2011, 4, 3966-3970.

29 R. Subbaraman, D. Tripkovic, K.-C. Chang, D. Strmcnik, A. P. Paulikas, P. Hirunsit, M. Chan, J. Greeley, V. Stamenkovic and N. M. Markovic, Nat. Mater., 2012, 11, 550-557.

30 J. Rossmeisl, A. Logadottir and J. K. Norskov, Chem. Phys., 2005, 319, 178-184.

31 J. Rossmeisl, Z. W. Qu, H. Zhu, G. J. Kroes and J. K. Norskov, J. Electroanal. Chem., 2007, 607, 83-89.

32 B. Hammer, L. B. Hansen and J. K. Norskov, Phys. Rev. B: Condens. Matter, 1999, 59, 7413-7421.

33 F. Calle-Vallejo, J. I. Martinez, J. M. Garcia-Lastra, J. Rossmeisl and M. T. M. Koper, Phys. Rev. Lett., 2012, 108, 116103.

34 F. Abild-Pedersen, J. Greeley, F. Studt, J. Rossmeisl, T. R. Munter, P. G. Moses, E. Skulason, T. Bligaard and J. K. Norskov, Phys. Rev. Lett., 2007, 99, 016105.

35 M. T. M. Koper, J. Electroanal. Chem., 2011, 660, 254-260.

36 F. Calle-Vallejo, J. Ignacio Martinez and J. Rossmeisl, Phys. Chem. Chem. Phys., 2011, 13, 15639-15643.

37 S. D. Miller, N. Inoglu and J. R. Kitchin, J. Chem. Phys., 2011, 134, 104709.

38 M. Garcia-Mota, M. Bajdich, V. Viswanathan, A. Vojvodic, A. T. Bell and J. K. Norskov, J. Phys. Chem. C, 2012, 116, 21077-21082. 